MENTAL HEALTH NURSING 


\title{
Mental Health Nursing
}

\section{Competencies for Practice}

\author{
Edited by \\ Stephan D. Kirby, \\ Denis A. Hart, Dennis Cross \&
}

Gordon Mitchell 


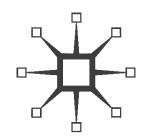

(c) Stephan D. Kirby, Denis A. Hart, Dennis A. Cross \& Gordon Mitchell 2004 Individual chapters (C) contributors 2004

All rights reserved. No reproduction, copy or transmission of this publication may be made without written permission.

No paragraph of this publication may be reproduced, copied or transmitted save with written permission or in accordance with the provisions of the Copyright, Designs and Patents Act 1988, or under the terms of any licence permitting limited copying issued by the Copyright Licensing Agency, 90 Tottenham Court Road, London W1T 4LP.

Any person who does any unauthorized act in relation to this publication may be liable to criminal prosecution and civil claims for damages.

The authors have asserted their rights to be identified as the authors of this work in accordance with the Copyright, Designs and Patents Act 1988.

First published 2004 by

PALGRAVE MACMILLAN

Houndmills, Basingstoke, Hampshire RG21 6XS and

175 Fifth Avenue, New York, N.Y. 10010

Companies and representatives throughout the world

PALGRAVE MACMILLAN is the global academic imprint of the Palgrave Macmillan division of St. Martin's Press, LLC and of Palgrave Macmillan Ltd. Macmillan ${ }^{\circledR}$ is a registered trademark in the United States, United Kingdom and other countries. Palgrave is a registered trademark in the European Union and other countries.

ISBN 978-1-4039-0262-7 ISBN 978-1-4039-9756-2 (eBook)

DOI 10.1007/978-1-4039-9756-2

This book is printed on paper suitable for recycling and made from fully managed and sustained forest sources.

A catalogue record for this book is available from the British Library.

$\begin{array}{llllllllll}10 & 9 & 8 & 7 & 6 & 5 & 4 & 3 & 2 & 1\end{array}$

$\begin{array}{llllllllll}12 & 11 & 10 & 09 & 08 & 07 & 06 & 05 & 04 & 03\end{array}$ 


\section{Contents}

List of Figures

xiv

List of Tables

$\mathrm{XV}$

List of Boxes

xvi

Foreword

Xvii

Stephan D. Kirby and Gordon Mitchell

Notes on the Contributors

$\mathrm{xx}$

Introduction

xxviii

Stephan D. Kirby, Denis A. Hart, Dennis Cross and Gordon Mitchell

PART I

BACKGROUND TO GOOD PRACTICE AND

EFFECTIVE LEARNING

1 Developing a Competence-based 'Exit Profile' for

Pre-registration Mental Health Nursing

Dennis Cross and Elaine Readhead

Competencies for Entry to the Register

Conclusions

2 The Recognition of Inequality and the

Need for Empowerment

Denis A. Hart

Introduction

Prejudice and discrimination

3 How Can Nurses Meet the Needs of Mental

Health Clients?

Sue Jackson and Chris Stevenson

Introduction

How the study was organized

Data analysis

Findings and discussion

Conclusion (and implications of the study)

Note 
4 User Perspective - The Good Psychiatric Nurse

Anne Maidment

5 Carer Issues in Mental Health

Val Chapman

6 Working with People who have Special Needs and

Disabilities and Mental Health Problems

Celia Harbottle and David Mudd

Introduction

A critical review of definitions of special needs, disabilities and mental health and the limitations imposed by language $\quad 67$

The social model of disability and its relevance to mental health nursing practice

The evolution of contemporary attitudes to people with disabilities

Conclusions

PART II

PREVENTION AND HEALTH PROMOTION

7 Common Mental Health Problems

Denis A. Hart

Introduction

Normality and abnormality

Mental disorder, anti-social behaviour and the law

The role of mental health nurses

The classification of mental and behavioural disorders

Common mental health problems

Conclusions

8 Mental Health Promotion

Dennis Cross

Introduction

Defining mental health

What is meant by mental health promotion? 96

Mental health promotion and social exclusion

The relationship between mental health, wellness and mental illness

Education and training

Mental health promotion or mental health education?

Research and evaluation 
9 A Positive Approach To Mental Health Nursing: Role, Values and Attitudes

Dennis Cross

What are the outcomes of mental health/psychiatric nursing? 108

Conclusion

10 Risk Prevention

Denis A. Hart and Stephan D. Kirby

Introduction

What is risk?

Risk assessment

Principles of risk assessment

Models of clinical risk assessment and predication

Risk management

The community safety agenda

Conclusion

11 Creating and Maintaining a Safe Environment

Neil Woodward, Lyn Williams and Peter Melia

Dimensions of risk to self (suicide and self-injuriousness): what the boffins tell us

An environmental response

Dimensions of risk to others (dangerousness)

Conclusion

\section{PART III}

CONTINUUM OF TREATMENT

12 Interdisciplinary Approaches to Community

Mental Health Practice

Denis A. Hart and Angela Hall

Introduction

Models of service provision

A framework for the delivery of secondary mental health care

Managing risk

Conclusion

13 Supporting People and their Families During

Psychopharmacotherapy

Mike Fleet

Introduction

The challenge of serious mental illness 
Informed consent and autonomy

Psychopharmacology and psychopharmacotherpy

Symptom monitoring and management tools

Monitoring negative effects

The working alliance

Psychoeducation

Strategies for improving medication compliance

Conclusion

14 Using Counselling in Mental Health Practice

Maggie Hadland

Introduction

What is counselling - just tea and sympathy?

The core conditions

Counselling approaches

The process of counselling: beginning, sustaining and closing the therapeutic relationship

15 Some Brief Psychological Therapies

Jan Connolly and Sheila Arnold

Introduction

The generation of hope

Empowering the client in the course of therapy

Brief psychological therapies and psychopharmacotherapy

Conclusion

16 Person-centred Approach to the Care of Older People

With Mental Health Problems

Liz Desira and Geoff Martin

Introduction

Person-centred care

The role of ageism

Common mental health problems

Care interventions

Personhood

Conclusion

17 Treating Post Traumatic Stress Disorder

Gillian Green

Introduction

Historical perspective/changing attitudes

What constitutes a 'traumatic event'?

Different reactions to trauma experiences

Associated symptoms

Co-morbidity and associated problems 
$\begin{array}{ll}\text { Prevalence rates } & 234\end{array}$

Assessment issues/approach $\quad 234$

$\begin{array}{ll}\text { Assessment measures } & 234\end{array}$

Treatment approaches $\quad 235$

Conclusion 236

18 Assessing and Engaging People with Personality Disorder 241

Peter Melia and Stephan D. Kirby

Introduction 241

Dilemmas in defining psychopathy and personality disorder 243

Classification and description - medical $\quad 244$

Classification and description - psychological 246

A word on the judiciary and DSPD 251

Working with personality disordered clients $\quad 252$

Dynamic issues and relationship as a therapeutic tool 253

$\begin{array}{ll}\text { Splitting and secrets } & 255\end{array}$

$\begin{array}{ll}\text { Rejection } & 256\end{array}$

$\begin{array}{ll}\text { Conclusion } & 258\end{array}$

19 The Influence of Dual Diagnoses 260

Dominic Wake

Introduction $\quad 260$

Prevalence $\quad 262$

Violence and offending $\quad 262$

$\begin{array}{ll}\text { Motivation } & 264\end{array}$

$\begin{array}{ll}\text { Therapeutic strategies } & 264\end{array}$

$\begin{array}{ll}\text { Accurate assessment } & 268\end{array}$

Families and significant others $\quad 269$

$\begin{array}{ll}\text { Conclusion } & 270\end{array}$

20 Psychosocial Interventions for People with Serious

Mental Illness

Mike Fleet

$\begin{array}{ll}\text { Introduction } & 273\end{array}$

$\begin{array}{ll}\text { The role of engagement } & 274\end{array}$

$\begin{array}{ll}\text { Psychoeducation } & 274\end{array}$

$\begin{array}{ll}\text { Working with families } & 275\end{array}$

Individual approaches to psychotic phenomena 276

Cognitive-behavioural approaches to psychotic phenomena $\quad 280$

$\begin{array}{ll}\text { Conclusion } & 285\end{array}$

21 Mental Health Nursing within Secure Conditions 290

Stephan D. Kirby and Denis A. Hart

$\begin{array}{ll}\text { Introduction } & 290\end{array}$

The forensic nursing role and the law 291 
The General Duty of Care as applied to secure facilities

The General Duty of Care and forensic mental health nursing 293

Forensic nursing and ethics

The emerging role of the forensic mental health nurse 294

The public perception 296

Relationships 297

Ensuring care needs are met in secure facilities 299

Assessment of risk $\quad 300$

Assessing patients' needs 301

Forensic mental health nurse competencies and education 301

$\begin{array}{ll}\text { Conclusion } & 302\end{array}$

22 Acute In-patient Setting 307

Gordon Mitchell, Chris Stanbury and Sheila Arnold

Introduction $\quad 307$

The role of the newly qualified nurse in an acute
in-patient setting

An example - practice development 308

Ongoing modernization and governance agendas $\quad 310$

Models for mental disorder 311

Working with clients and their families within acute $\begin{array}{ll}\text { in-patient care } & 314\end{array}$

$\begin{array}{ll}\text { Conclusion } & 327\end{array}$

23 Assertive Community Treatment with People

Experiencing Serious Mental Illness

Mike Fleet

Introduction $\quad 335$

The historical perspective $\quad 336$

Definition of ACT 337

The benefits of ACT 338

Model fidelity 341

Target client group $\quad 342$

Evidence-based interventions in ACT 342

Ethical issues in ACT 344

Conclusion 346

24 Mental Health and Community Safety 349

Denis A. Hart and Stephan D. Kirby

Introduction 
PART IV

USING EFFECTIVE LEARNING TO DEVELOP REFLECTIVE PRACTICE

25 Legal and Professional Issues in Mental Health

Nursing Practice

Gordon Mitchell

Introduction

Accountability

What is a duty of care? 358

Negligence $\quad 359$

$\begin{array}{ll}\text { Consent } & 360\end{array}$

Competency 362

Who can give consent? 364

Mental Health Act (1983) 365

Psychiatry and criminal law $\quad 367$

Sentencing mentally disordered offenders under the Mental Health Act (1983) 369

$\begin{array}{ll}\text { Conclusion } & 369\end{array}$

26 Management Issues in Practice 371

James T. Watson

Introduction 371

Leading $\quad 374$

Controlling $\quad 375$

Recipient and user evaluation of services $\quad 378$

Data collection and its uses $\quad 379$

Conclusion 381

27 Facilitating Multi-disciplinary Relationships and Practice 383 Maggie Hadland

Introduction $\quad 383$

Multi-professional practice $\quad 384$

Some suggestions for better multi-professional working $\quad 386$

Self-presentation $\quad 387$

Perception and attribution $\quad 389$

Groups and teams 391

Using interpersonal skills effectively $\quad 395$

28 The Evidence Base 400

Angela Morgan and Chris Stevenson

What is evidence-based practice? $\quad 401$ 
What constitutes evidence? $\quad 404$

Sources of evidence $\quad 409$

How can EBP be incorporated into mental health nursing? 411

29 Learning: from Self-development to Competency

Stephan D. Kirby and Denis A. Hart

Introduction

Learning

Self-assessment

Self-development

The exit profile portfolio

Learning opportunities and practice skills

Learning opportunities and the learning experience

Learning opportunities and values

Learning opportunities and anti-discriminatory practice

30 A Framework for Success: A Student's Perspective Colin Rowley

31 A Day in the Life of ...

Mike Firn, Steve Harrison and Peter Melia

Working in Assertive Outreach

Mike Firn

Introduction

Generic working

Assertive Outreach person specification

Communication and structuring the work

Engagement

Symptom management

Conclusion

Nursing Young People with Mental Health Problems

Steve Harrison

Introduction

Initial reflections

Basic principles

Implications for practice

Reflections of a Forensic Mental Health Nurse 
Overview

464

Stephan D. Kirby, Denis A. Hart, Dennis Cross, and Gordon Mitchell

Appendix: A Competence-based 'Exit Profile' for Pre-registration

Mental Health Nursing

Index 


\section{List of Figures}

1.1 The process used in the construction of an 'exit profile' plan 7

3.1 The three me's 34

8.1 The links between well-being and ill-health 99

11.1 The aggression cycle 139

13.1 Neurotransmission across synapse 167

18.1 Chart of interpersonal relationships in a closed living environment 249

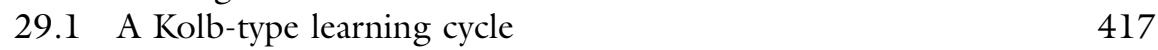

29.2 Revised learning cycle 418

29.3 Honey and Mumford's four learning styles 418

29.4 Two routes to self-development 419

29.5 Competence 421

29.6 Kolb's cycle of competence 422

29.7 The role of opportunities in the learning experience 429 


\section{List of Tables}

10.1 Three models of clinical risk assessment

10.2 The areas deemed necessary for an effective risk management plan

12.1 Theory of preventative psychiatry

12.2 The two levels of care co-ordination

16.1 Summary of symptoms of Alzheimer's Disease

18.1 DSM-IV Axis II diagnoses

18.2 Categorical evaluation of psychopathy

18.3 The 'big five' factors

21.1 Competency Framework 2000

25.1 Some sections of the Mental Health Act (1983)

27.1 Approaches to dealing with conflict situations

29.1 Key to essential evidence

31.1 Assertive Outreach person specification 


\section{List of Boxes}

31.1 Format for handover/briefing

31.2 Functions of handover/briefing 


\section{Foreword}

\section{Stephan D. Kirby and Gordon Mitchell}

At a meeting of mental health educators in November 1999 a recommendation was made that it would be extremely helpful to develop a subset of the UKCC competencies specifically for mental health nurses. The project to develop these competencies was instigated by The Northern Centre for Mental Health.

So, not long after that meeting a group of leading clinicians, academics, service providers and service users from the North East of England met to discuss and plant the seeds of what was to become the 'Competence-Based "Exit Profile" For Pre-Registration Mental Health Nursing'. It was evident at that stage that something innovative was needed to capture the complexities of mental health nursing and mental health nurse education in the twenty-first century.

It is not our intention to maintain a cliché nor to state an obvious truism when we echo the words of Martin Brown (Co-Director of the Northern Centre for Mental Health) when he said that 'tomorrows services will be run, managed and led by today's learners'. It is therefore essential that they receive the proper and timely preparation for their future roles and continual personal and professional development through lifelong learning. The competencies highlighted within this text are designed to show the starting point of the professional journey and will help educators plan curricula, which engage, encourage and enliven learners through a variety of educational activities.

The principle behind the development of the 'Exit Profile' was to ensure that there is consistency in the essential knowledge, skills and attitudes that mental health nursing students will acquire by the end of their educational programmes, while maintaining an acceptable level of flexibility to be responsive to local needs. The developers engaged a partnership approach to curriculum development, which meant that the Curriculum Development Team consisted of not only Mental Health Lecturers, but also clinicians from our local NHS Trusts, the views of previous student nurses and users and carers of local mental health services.

The development of the 'Exit Profile' acknowledges the drive for quality in the NHS, which includes the changing context of mental health care delivery described in the National Service Framework for Mental Health (DoH, 1999a). The domains and benchmarks within the 'Exit Profile' (See Appendix $l$ of this text) are provided to assist curriculum and planning groups in the construction of contemporary pre-registration mental health nursing education programmes, which have an overall aim of preparing mental health nurses to be fit for practice, purpose and award upon registration. 
With the publication of Making a Difference (DoH, 1999b), and Fitness for Practice (UKCC, 1999) the School of Health and Social Care within the University of Teesside was successful in being chosen as a pilot site to introduce the 'competency-based approach' to Pre-Registration Nurse Training. These reports along with the Requirements for Pre-registration Nursing Programmes (UKCC, 2000) provided a contemporary framework for the development of nursing and midwifery programmes based upon a new outcomes and competency approach. The recommendations published in these reports provide generic competencies for entry to the register that have been used as a foundation to construct specific benchmarks for the mental health branch of nursing.

In developing our curriculum we used the Fitness for Practice (UKCC, $1999, \mathrm{p} 35$ ) definition that described competence as the 'skills and ability to practice safely' and is 'fundamental to the autonomy and accountability of the individual practitioner and therefore to their code of conduct'. Therefore, this competency-based approach to education and the development of the 'Competence Based Exit Profile' (the nucleus and focal point for this text) will encourage the development of the knowledge, understanding, practical and technical skills, attitudes and values of the student nurses who, over a three year period, will work with, as well as support, all those professionals with a responsibility for developing and delivering pre-registration mental health nursing programmes.

Once successfully approved by our internal and external validation bodies it was clearly that the new 'Making a Difference' $(\mathrm{MaD})$ (no pun intended!) Mental Health Student Nurse Training Programme was radically different to our previous programmes. The first two cohorts for this programme commenced (for the Degree Pathway) in September 2000 and (for the Diploma Pathway) in January 2001. These students, including one of this text's authors, are being monitored and evaluated by a national research programme, funded by the Department of Health and are due to qualify soon. But our intermediate evaluation is very positive with practitioners reporting a more competent and skilled student nurse working on the clinical areas. Therefore, this book, as well as being based upon the mental health competencies, is also a reflection of this innovative mental health student nurse preregistration programme.

While the editors and contributors see the readership of this text as being (primarily though not exclusively) the mental health student nurse undertaking the Making a Difference Mental Health programmes, we also feel that this book is very useful to a wider range of other mental health clinicians from the newly qualified nurse through to the experienced nurse who acts as a Practice Mentor for the aforementioned students when they undertake their practice. We also hope that this text will help coordinate the practice experience and assist clinical settings to develop their sites and to assist in enhancing further the students' learning experience.

The contributors (apart from those who provide education at the University 
of Teesside) are drawn from a range of specialities and services around the UK and range of clinical experiences.

Readers should be aware that while each chapter carries benchmarks (taken from the Exit Profile) which are indicative to the theoretical content, one domain was not included (Domain 1.1 Professional Practice), this is due to the fact that we feel that this domain and its inherent benchmarks are intrinsic to all the chapters in this text and therefore to include them in the tables at the head of each chapter would have been just added to the bulk of benchmarks already there, this is why the observant among you - those of you who intend to 'map' the chapter benchmarks to the framework (in the Appendices) you will not find these particular benchmarks for achievement highlighted as being specific to any particular chapter.

We hope that you, the reader, will find the contents of this book interesting, illuminating and provoking a variety of questions and a desire to find out more, which will motivate you to read further texts on the variety of subjects covered here. We are not intending to provide all the answers to questions, rather we would like you to use this book as a 'springboard' to further reading for your personal and professional development.

We hope you enjoy what you read from here forward.

Stephan D. Kirby, Gordon Mitchell, Dennis Cross \& Denis A. Hart

\section{References}

Department Of Health (1999a) National Service Framework for Mental Health, London: HMSO.

Department of Health (1999b) Making A Difference: Strengthening The Nursing, Midwifery and Health Visiting Contribution To Health and Health Care, London: HMSO.

United Kingdom Central Council For Nursing, Midwifery and Health Visiting (1999) Fitness For Practice, London: UKCC.

United Kingdom Central Council For Nursing, Midwifery and Health Visiting (2000) Requirements for Pre-registration Nursing Programmes, London: UKCC. 


\section{Notes on the Contributors}

Sheila Arnold: BSc (Hons), MSc, RMN, RGN, RNT, Cert Ed, Cert Coun, Dip Nursing, (PhD Student) is Senior Lecturer at the School of Health and Social Care, University of Teesside. She has over three decades of experience as a psychiatric-mental health nurse and educator. Sheila is a Registered Mental Health Nurse and Registered General Nurse and completed a Diploma in Nursing in 1980. In recent years her personal, professional research interests have been in relation to the experiences of nurses in the field of psychiatric care with a particular focus on 'therapeutic working' and 'therapeutic conversation'. Her Doctoral studies involve a discourse analysis of the experiences of nurses utilizing a psychosocial approach (PSI) to care of the individual and their families and carers.

Val Chapman taught modern foreign languages until she became a full-time carer in 1998. She now works as a volunteer with 'Rethink', the UK's largest mental illness charity, and is involved in carer support, campaigning for better services, and reducing stigma. She coordinates a support/campaigning group throughout County Durham, and is working in partnership with the local NHS Psychiatrist Trust to improve services to families. She has a particular interest in early intervention and has been involved in the Newcastle Early Psychosis Declaration, which is supported by the World Health Organization and is set to become an international benchmark for service providers. She has recently trained as an advocate and set up an advocacy service for members of the group.

Jan Connolly: BA (Hons), MA, RMN, PgCE, DPSN, RNT is Senior Lecturer in the School of Health and Social Care at the University of Teesside. Jan undertook her pre-registration training at the Maudsley Hospital, London and completed in 1982. She qualified as a Nurse Teacher in 1991. Her current role is Pathway Leader for the Advanced Diploma in Mental Health Nursing. She was formerly Clinical Nurse Specialist (Mood Disorders) and Honorary Lecture-Practitioner, Liaison Psychiatry. Specific professional interests include Cognitive Behaviour Therapy; Interpersonal Psychotherapy; Feminist approaches to Women's Mental Health Problems and Discourse Analysis.

Dennis Cross: TD, BA (Hons), BEd (Hons), MA, RMN, RGN, RNT, (PhD Student) (co-editor) is Principal Lecturer (Mental Health) School of Health and Social Care at the University of Teesside. He is currently completing his $\mathrm{PhD}$ in nursing education and mental health. He was the Project 
Leader for the development of the 'Exit Profile' working closely with Elaine Readhead, on behalf of the Northern and Yorkshire NHS Workforce Development Group and the Northern Centre for Mental Health. During part of academic year 2002/3 he has been seconded to the Institute of Technology in Tralee, Ireland to help to introduce a new pre-registration degree in Mental Health Nursing.

Liz Desira: BSc (Hons), MSc, RMN, RGN, RCNT, Cert Ed is a Senior Lecturer in the School of Health and Social Care at the University of Teesside. She undertook her pre-registration Adult Nursing at Mount Vernon Hospital Middlesex, her Midwifery training at the Simpson Memorial Maternity Pavilion, Edinburgh and Mental Health training at The Middlesex Hospital, London and Hill End Hospital, St Albans. After a short period working as an operating theatre sister she returned to mental health nursing. Her current employment includes (as well as being Senior Lecturer (Mental Health)) her role as Examinations and Assessments Officer for pre- and post-registration nursing studies at the University of Teesside. Specific professional interests include care of the elderly and health promotion.

Mike Firn: BA (Hons). RMN is a Mental Health Nurse with nine years experience using the Assertive Community Treatment model in the UK. He is the Service Manager for 3 ACT Teams in South West London, as well as Home Treatment and Early Intervention Services. Mike is coordinator of the London Region for the National Forum for Assertive Outreach. He has coauthored with Prof. Tom Burns, the book Assertive Outreach in Mental Health, a manual for practitioners, published by Oxford University Press (2002).

Mike Fleet: BSc, MSc, RMN, RGN, PgCE, Dip Thorn is a Senior Lecturer, at the School of Health and Social Care, University of Teesside. Mike is module leader for several programmes including 'Integrated Approaches and Interventions with People with Serious Mental Illness and Their Families', 'Multidisciplinary Assertive Outreach for the Severely Mentally Ill' and 'Awareness of Psychosocial Interventions'. Previously Mike was Clinical Nurse Specialist with the South West London and St George's Hospital Mental Health NHS Trust's Assertive Community Treatment Team. He is currently developing a degree in 'Evidence-based Interventions in Mental Health and Social Care' to promote evidence-based practice at a clinical level. Mike is a member of the British Association for Behavioural and Cognitive Psychotherapies.

Gillian Green: BSc (Hons), RMN, Dip Nursing, (PhD Student) is the Specialist Clinical Practitioner at the Duchess of Kent's Psychiatric Hospital, Catterick Garrison, North Yorkshire. Her role has focused on psychological injury for the past six years. She has been instrumental in the establishment 
an ongoing development of a Defence Medical Services Unit dedicated to the assessment and treatment of psychological injury resulting from traumatic experiences. Her keen interest in the professional development of both herself and others has enabled her to design and implement an evidence-based six month rotational training programme for Registered Mental Health nurses in the assessment and treatment of psychological injury. In addition to this she has also developed and presented a number of workshops and educational packages focusing on various aspects of stress and trauma across a range of both health care and non-health care professionals. Gillian is also a member of the International Society of Traumatic Stress Studies (ISTSS), which has afforded her a number of opportunities not only to share her research interests, but also to present the model of care used by her and her colleagues on a national and international level. In addition she is also a member of the British Association of Behavioural and Cognitive Psychotherapy (BABCP).

Maggie Hadland: BA (Hons), MA (Ed), RMN, RGN, RNT, Cert Ed is a Senior Lecturer in the School of Health and Social Care at the University of Teesside. After obtaining a first degree in Sociology, Maggie trained in both Adult and Mental Health Nursing, and has worked in a variety of Acute Mental Health settings, including managing a 29-bed acute in-patient facility. Maggie is also a qualified counsellor, having received her Masters in Counselling from Durham University, and was responsible for implementing and operating a counselling service in five schools for children and young people aged 9 to 18. Maggie continues to practice counselling with children in a local primary school. Her current teaching includes providing the input on Humanistic Counselling approaches to the MSc in Counselling and Counselling Psychology, as well as teaching counselling skills to nurses and other health professionals. At the moment she is studying for a Post-Graduate Diploma in Psychology, and is researching changes in visual-spatial ability over the menstrual cycle. Other research interests are adult attachment and women and mental health.

Angela Hall: BSc (Hons), MA, RMN, RGN, RNT, PgCE, Cert Coun, App Dip (PhD Student) is a Senior Lecturer (Mental Health) in the School of Health and Social Care, University of Teesside. Angela is Programme Leader for the Joint Social Work/Mental Health Nursing framework at preregistration, the first in the UK. Having qualified in both Mental Health and General Nursing she practised as a Community Mental Health Nurse, first within Primary Care and more recently as part of a Community Mental Health Team. She became a nurse educator in 1992 and her current interests are in Inter-professional Working and Education, Primary Mental Health Care and Psychosocial Interventions for People with a Serious Mental Illness. Her PhD studies are focused on the students development of a 'Shared Professional Identity'. 
Celia Harbottle: BA (Hons), MA, CSS, Cert is a Senior Lecturer in Social Work/Learning Disability Nursing at the School of Health and Social Care, University of Teesside. She is also Programme Leader for awards offering both nursing and social work qualifications. Her research interests are integrated working, competency frameworks in vocational education and social care practice. She is also a fellow of the Royal Society of Arts.

Stephen Harrison: BSc Hons, RMN, Dip CAMH (ENB 603), Dip CMHN is a Nurse Consultant working at the Newberry Centre for Young People in Middlesbrough (Tees and North East Yorkshire NHS Trust). He took up the post in September 2002. Born and raised in Teesside, his career began as a Nursing Assistant working with teenagers in 1979. He trained at St Luke's Hospital and went on to study Nursing to Degree Level at the University of Teesside. Steve has nursed and managed in residential and community settings with young people as well as contributing to the Health Advisory Service Thematic Review - 'Together We Stand' - and contributing to the Department of Health's Children's National Service Framework. Steve is also a part time lecturer at the University of York teaching on the Child and Adolescent Mental Health Degree Pathway.

Denis A. Hart: MPhil, MA/CQSW, MA, BSc. (Soc), MBSA, (co-editor) is a Visiting Lecturer at the School of Health and Social Care, University of Teesside. Prior to this Denis was Houseparent at Kingswood School in the late 1960s and early 1970s before becoming House-warden at Tennal Assessment Centre from 1970 to 1971 . He then entered academia and was Lecturer in Social Work (University of Bristol, 1971-73), he then became Deputy Head at Aycliffe Assessment Centre in County Durham (1973-81) becoming Head of the Centre between 1981 and 1985. In 1985 he returned once again to academia when he became Principal Lecturer at Trent Polytechnic. He moved to the University of Teesside in 1991 when he became the Principal Lecturer (Social Work) until 1997. From then to the present date, Denis has been a Research Associate working with the University of Teesside. As well as producing a wealth of Open Learning materials for a variety of programmes within the School of Health and Social Care, Denis is also a Trustee for the Resource Network for Disordered Adolescents, he monitors Bail support for NACRO and the Youth Justice Board and is working on developing protocols with the local Youth Offending Team.

Sue Jackson: RGN, BSc. (Hons), MPhil trained as an RGN in London and worked predominantly in head injury and neuro-oncology in London then moved to Addenbrookes in Cambridge where she completed the ENB 148 (Neuro-medical, Neuro-surgical Nursing). Sue has travelled and worked in Australia for 3 years. On her return, she studied for her BSc. (Hons) (Health Studies) at East Anglia Polytechnic University. Sue then moved 
to Newcastle and joined the Department of Psychiatry in 1995, where she has undertaken a number of research studies in mental health issues in nursing. Working with Prof. Phil Barker and Dr Chris Stevenson, she was involved in the 'Need for Nursing Studies'. Sue's MPhil Thesis 'What Do People Need Psychiatric and Mental Health Nurses For' was one of a collection of studies which formed the underpinning framework for the Tidal Model of Nursing (Barker, 2000).

Stephan D. Kirby: MSc, PgC (L\&T), Dip MDO, RMN (PhD Student) (co-editor) is a Senior Lecturer (Forensic Health and Social Care) in the School of Health and Social Care at the University of Teesside. He has nearly three decades of experience working with the mentally ill, the largest part being within Forensic Mental Health Services. He is Programme Leader for a number of post-registration educational pathways as well as numerous other pathways and modules ranging from Level 1 through to Masters level. The research for his MSc Thesis looked at Cognitive Distortions in Child Sexual Offenders. Currently he is studying for his $\mathrm{PhD}$, which is exploring the experiences of 'Life in a Category A Segregation Unit'. Steve is also the current Chair of the National Forensic Nurses' Research and Development Group (www.forensicnurse.org.uk) and is also (Non-Executive) Director of Nursing for Veritas Management Ltd. Veritas provides highly experienced staff to all types of healthcare services. It specializes in secure environments, especially Police Nurses, and HMP Service with the provision of Custody Nurses and Forensic Medical Examiners.

Anne Maidment: MA, BA, Cert Ed is a user of mental health services in the North East of England. She describes her mental illness (bipolar disorder) first becoming apparent after the birth of her son. She describes her interests and activities as: Political - has been a constituency Chair for 18 months and on the Executive for 8 years; Trade Union - regional Vice Chair and National Council Member for NATFHE and helped to establish the Retired Members Section; Misc. she has been a Community Health Council member for 6 years and a member of the Committee of Sunderland Art Studio. Anne is also a member of Headlight - Sunderland's Mental Health Resource Centre. She retired, on health grounds, in 1992.

Geoff Martin: RGN, RMN, BSc (Hons), MA has worked in Mental Health Nursing and with the care of older people in Leicester and Middlesex Hospitals before moving into education as Staff Development Officer at Bishop Auckland General Hospital. He joined the University of Teesside in the mid 1990s, and is presently Team Leader for the Adult Nursing Team. His research has been around empowerment of dying patients and more recently working with an audit programme in North Durham using Dementia Care Mapping. The project attempted to measure the level of person-centred care provided by the Mental Health Trust in the area and the work has been published in a series of papers in national nursing journals. 
Peter Melia: BA (Hons), MA, RMN, PgCE, PgCPD is the Nurse Consultant (Forensic Service), at the The Hutton Centre, St Luke's Hospital, Middlesbrough (Tees and North East Yorkshire NHS Trust). He has worked in forensic mental health services for more than two decades and has considerable experience in both health service management and clinical practice. $\mathrm{He}$ has contributed significantly to the development of PSI type (poly-factorial) approaches in working with individuals who suffer serious mental illness and personality disorder.

Gordon Mitchell: BSc (Hons), MA, RMN, Dip Nursing, ILTM, (coeditor) is a Senior Lecturer and Pathway Leader for Pre-Registration Mental Health Nursing in the School of Health and Social Care at the University of Teesside. He has responsibility for the implementation of the Making a Difference programme for Pre-Registration Mental Health Nurse Training. Specialist areas for teaching, are Mental Health Law, Care of the Client in a Acute Mental Health Setting. He has been working with the local Mental Health Trust on a project to implement 'Essence of Care' and with the Older Person Unit, which successful achieved Practice Development Unit Status. Gordon's clinical background, since qualifying includes working with clients in an acute mental health setting until 1992, when he entered education, however he still maintains clinical links with an acute admission unit where he spends time working with staff and student nurses on the complexities of this client group.

Angela Morgan RGN, RM, Cert Ed, BSc. (Hons) MSc is a Principal Lecturer, currently working in the role of Learning and Teaching Co-ordinator in the School of Health and Social Care at the University of Teesside. She is a Nurse and Midwife and retains a commitment to facilitating learning for a wide range of health professionals in the field of research methods and evidence-based practice.

David Mudd: MSc, RMN, RNMH, Cert Ed, Dip CPN is the Principal Lecturer, for Learning Disability in the School of Health and Social Care, University of Teesside. His research interests include evaluating the influence of service-user involvement in the development, delivery and evaluation of health and social care educational curricula. He is currently involved in curriculum developments related to integrated approaches to health and social care and working across organizational and professional boundaries.

Elaine Readhead: BA (Hons), MA, RMN, Dip CPN is a Project Manager for the Northern Centre for Mental Health - A Regional Development Centre for the National Institute for Mental Health (England) (NIMHE). Elaine started work in the National Health Service in 1981 as a Registered Mental Nurse. She has a wide range of experience in a variety of community settings. She has also worked as a Mental Health Training Co-ordinator for a local Workforce Development Confederation. She currently manages projects relat- 
ing to mental health education, training and workforce development. Elaine is also a Visiting Fellow at Teesside University.

Colin Rowley is a student nurse on the BSc (Hons) Nursing Studies (Mental Health) course at the University of Teesside and is due to graduate in 2003. $\mathrm{He}$ is a member of the first cohort to undertake the Making a Difference programme - which is underpinned by the Exit Profile explored within this text. At the time of writing he is in his third year, having lived through the experience of writing two portfolio's and is currently engaged in his third. His experience throughout the course has ranged from acute settings through to high and medium secure forensic settings. He sees his immediate future in acute nursing with a long-term view of working in community settings. He is currently undertaking his dissertation examining the interface between primary and secondary care.

Chris Stanbury: RMN, BSc (Psychotherapy), MEd is a registered mental health nurse and came into nursing as a psychology graduate and now has over 20 years of experience of nursing practice. She holds a second registration in psychodynamic psychotherapy and a Masters Degree in Education. She has special interests in clinical supervision and nursing practice development and has worked in nurse education and acute mental health as a Nurse Specialist. Her current post in the Mental Health and Learning Disabilities Trust in County Durham and Darlington is Deputy Director of Nursing.

Dr Chris Stevenson: RMN, BA (Hons), MSc (Dist), PhD is Reader in Nursing at the University of Teesside. The focus of her scholarship was on describing the nature of nursing, the nature of nursing research and scholarship and the nature of nurse education/training, from within the postmodern turn. Chris has a keen interest in social constructionism in relation to the practice of family therapy, especially with people in eating distress, a further research interest. She has worked closely with Prof. Phil Barker in developing and evaluating the Tidal Model of Psychiatric Nursing, which has a developing profile nationally and internationally. Chris has an extensive publication profile, which includes many papers that challenge received nursing wisdom.

Dominic Wake: BSc (Hons), MSc, RMN, RGN is a Senior Lecturer in the School of Health and Social Care, University of Teesside. Dominic worked for 3 years in Acute Psychiatry at Guy's Hospital where he developed an interest in substance use by instigating sessional work with heroin users in and around Deptford. He then joined the Community Drug Team which covered Lewisham \& Southwark for 3 years. He then developed and managed a new Methadone Dispensing Programme before moving back to the North East, where he developed a three year alcohol home detoxification service. Dominic then managed the in-patient detoxification beds at Hartlepool General Hospital before moving to Guisborough to manage the Community Drug Team 
in Redcar \& East Cleveland. For the past couple of years, his main interest has been with parents and families of drug-users and how services provide support for them.

James T. Watson: RGN, ONC, RCNT, RNT Dip Nursing, MBA, MA, BEd (Hons), Dip (Pg) is Senior Lecturer and Pathway Leader for the Management Pathway within the BSc (Hons) Promoting Practice Effectiveness at the School of Health and Social Care, University of Teesside. James' career in Nursing has covered a wide range of areas from General Nursing, Paediatric Nursing, Learning Difficulties to Mental Health care. In the latter part of his career he has focused on the subject of management applied to the NHS and Nursing. James' work within the Colleges of Nursing and over the past 10 years the School of Health and Social Care at the University of Teesside, has enabled him to teach a wide area of management subjects from Certificate to Masters level within the context of the NHS and in particular the Nursing Profession.

Lyn Williams: MSc, Dip HE, RMN, HNC is Consultant Nurse, Liaison Psychiatry for Tees and North East Yorkshire NHS Trust. She qualified as an RMN in 1992 and worked within acute inpatient admission areas for elderly mentally ill and acute general psychiatry. Lyn began working in Liaison Psychiatry in 1996 when Liaison Psychiatry was first established in Middlesbrough. Liaison Psychiatry is a relatively new concept of mental health nursing and today is increasingly being acknowledged as a specialism within mental health nursing. Within her current role she has developed partnership working within Cancer Care at the local Acute Trust. This work was undertaken in the form of project work initiating a 'nurse to nurse' fast track referral route for mental health assessment for patients diagnosed with breast cancer and presenting mental health problems. Other areas of interest include, the development of an Integrated Care Pathway (ICP) in conjunction with the local Acute Trust for those presenting following an act of deliberate self harm. The main aims of the ICP is to improve the quality of the patient journey through the Acute Trust, prevent repetition, identify those at high risk of suicide, identify new mental illness. Also, in light of the National Suicide Prevention Strategy, establishing a multi agency task force to address suicide on Teesside and finally developing national core competencies for nurses wanting to pursue a career in Liaison Psychiatry.

Neil Woodward: RMN; Cert Ed; RCNI has a long history of working in forensic mental health care and is currently responsible for the management of the 'Aggression Management Training Centre' for the Tees \& North East Yorkshire NHS Trust. He is an experienced Trainer, practitioner and lecturer in aggression management techniques and theory and has provided personal safety and aggression management training to a variety of health care personnel, both nationally and internationally. 


\title{
Introduction
}

\author{
Stephan D. Kirby, Denis A. Hart, Dennis Cross and \\ GORDON MITCHELL
}

The principal aim of this text is to provide student mental health nurses with the necessary foundation knowledge required to enable them to integrate theory and practice when evidencing competence. The text is further designed to provide current practice mentors with a contemporary knowledge base to enable them to both evaluate performable, and to assist those on the practice placements to develop the required theoretical, connections.

In recent years, mental health nurse training has developed significantly from hospital-based training to academically based Schools within the Higher Education Sector. With this transition mental health nursing was transformed from a day-to-day operational context to fully fledged graduate level training programmes.

This transition occurred quite rapidly and saw the development of benchmark criteria as performance indicators of the competences to be developed and acquired. This has created a real void in terms of the adaptation of existing practical nursing knowledge and theoretical underpinning to focus specifically on enabling students to integrate theory, values and praxis into evidenced competence in practice.

The text begins by recognizing the need for the contemporary mental health nurse to work effectively in partnership with service users and their carers in keeping with the National Service Framework for Mental Health (Department of Health, 1999). The 'Background to Good Practice and Effective Learning' section therefore introduces the reader to these themes as they are developed, first, by the Chapter on 'The Recognition of Inequality and the Need for Empowerment', which seeks to encourage students to explore their own value bases and then apply new knowledge to appraise individual, cultural and structural discrimination. The theme is continued when we explore the importance of service-user involvement in research within mental health is demonstrated in 'How Can Nurses Meet the Needs of Mental Health Clients?'. This chapter is based on a funded research study and we feel that its inclusion offers the reader a balance within the text between the theory and competency driven chapters. This reports a study that explored how mental health professionals, service users, ex-service users and carers perceived the needs of people in the psychiatric system. The section closes with valuable insights into contemporary mental health services and its practice from both a service user and a carer of a mental health service user. 
Although assessment is a key theme throughout the text, the authors recognize that this is a pre-requisite to any form of intervention or treatment. In Part II 'Prevention and Health Promotion, the chapter on 'Common Mental Health Problems' provides learners with a typology of conditions to enable them to make assessment evaluations that encapsulate need, risk and self-determination as well as the aetiology of the presenting problems. The themes of collaborative working, explorations of values and patient-centred care are continued through the chapters on 'Mental Health Promotion' and 'A Positive Approach to Mental Health Nursing: Role, Values and Attitudes'. The chapter 'Risk Prevention' addresses the need to balance, the rights of the patient, the needs of the patient and the potential costs to others, when determining an appropriate care plan. As mental health nurses work in the community as well as in residential settings the final chapter of the section addresses the crucial aspect of 'Creating and Maintaining a Safe Environment' without differentiating between patient or staff showing that the issues raised within the chapter are important to all of us within mental health services.

The third Part 'Continuum of Treatment' helps to provide a robust framework for effective practice and is further developed by revealing the key modalities of service delivery based upon appropriate diagnoses notably, 'Treating Post-traumatic Stress Disorder', 'Psycho-social Interventions for People with Serious Mental Health Problems', 'Brief Psychological Therapies' and 'Using Counselling in Mental Health Practice'. As risk is an additional theme that transcends contemporary practice there is a strong emphasis on the management of individuals in a variety of settings, hence this section also looks at 'Mental Health Nursing Within Secure Conditions', 'Assessing and Engaging People with Personality Disorder', 'Assertive Community Treatment...' and 'Interdisciplinary Approaches to Community Mental Health Practice'.

Given the need for both students and qualified mental health practitioners to engage in evidence based practice, this final Part deals with 'Using Effective Learning to Develop Reflective Practice' and how the student and their practice mentors can use the Competency Based Exit Profile to monitor the acquisition of new skills and to assess student practice. This section looks at issues as wide as 'Management for Practice' and 'Learning: from Selfdevelopment to Competency'. It also includes a 'hands on' perspective from a student of the first cohort of Making A Difference students, who offers his views on completing the competency based programme in 'A Framework for Success: A Students Perspective'. This Part, and the text, finishes with a collection of lived experiences from three senior practitioners from varied services, who are offering the reader 'A Day in the Life of ...'.

Throughout the text the emergence of the Multi-Agency Public Protection Panels (MAPPP's) are identified and the revised Mental Health legislation is anticipated and there is an emphasis on early intervention and public safety building upon the powers already contained in the Mental Health (Patients in the Community) Act (Department of Health, 1995). 
We hope this text will not only provide students with the necessary underpinning knowledge in one central point to enable them to become effective practitioners but that furthermore the text will assist mentors in their task of ensuring quality of the workforce and maintaining high standards of practice for the benefits of the public, carers, and most importantly the patients themselves.

\section{References}

Department of Health (1995) Mental Health (Patients in the Community) Act, London: HMSO. Department Of Health (1999) National Service Framework for Mental Health, London: HMSO. 